\title{
Impaired Functional Capacity Predicts Mortality in Patients with Obstructive Sleep Apnea
}

\author{
Shiraz A. Nisar ${ }^{1}$, Raghunandan Muppidi ${ }^{1}$, Sumit Duggal ${ }^{1}$, Adrian V. Hernandez ${ }^{2,3}$, Vidyasagar Kalahasti ${ }^{1}$, \\ Wael Jaber ${ }^{1}$, and Omar A. Minai ${ }^{4}$ \\ ${ }^{1}$ Heart and Vascular Institute, ${ }^{2}$ Department of Qualitative Health Sciences, Lerner Research Institute, and ${ }^{4}$ Department of Pulmonary, \\ Allergy, and Critical Care Medicine, Cleveland Clinic, Cleveland, Ohio; and ${ }^{3}$ Postgraduate School, Universidad Peruana de Ciencias \\ Aplicadas, Lima, Peru
}

\begin{abstract}
Background: Obstructive sleep apnea (OSA) is associated with increased mortality, for which impaired functional capacity (IFC) has been established as a surrogate. We sought to assess whether IFC is associated with increased mortality in patients with OSA and whether IFC is predictive of increased mortality after accounting for coronary artery disease.

Methods: Patients with OSA who underwent both polysomnography testing and exercise stress echocardiogram were selected. Records were reviewed retrospectively for demographics, comorbidities, stress echocardiographic parameters, and polysomnography data. Univariable and multivariable logistic regression analysis was used to evaluate the association between IFC and overall mortality. We then evaluated the variables associated with IFC in the overall population and in the subgroup with normal Duke treadmill score (DTS).
\end{abstract}

Results: In our cohort, 404 (26\%) patients had IFC. The best predictors of IFC were female sex, history of smoking, ejection fraction less than 55, increased body mass index, presence of comorbidities, abnormal exercise echocardiogram, abnormal heart rate recovery, and abnormal DTS. Compared with those without IFC, patients with IFC were 5.1 times more likely to die (odds ratio [OR], 5.1; 95\% confidence interval [CI], 2.5-10.5; $P<$ $0.0001)$ by univariate analysis and 2.7 times more likely to die (OR, 2.7; 95\% CI, 1.2-6.1; $P=0.02$ ) by multivariate analysis, when accounting for heart rate recovery, DTS, and sleep apnea severity. Among those without coronary artery disease, patients with IFC were at significantly increased risk of mortality (OR, 4.3; 95\% CI, 1.35-13.79; $P=0.0088$ ) compared with those with preserved functional capacity.

Conclusions: In our OSA population, IFC was a strong predictor of increased mortality. Among those with normal DTS, IFC identified a cohort at increased risk of mortality.

Keywords: sleep apnea; coronary artery disease; mortality; polysomnography; impaired functional capacity

\footnotetext{
(Received in original form September 17, 2013; accepted in final form June 5, 2014)

Author Contributions: S.A.N.: concept, data acquisition and interpretation, drafting, revising, final approval; R.M.: concept, data acquisition and interpretation, drafting, final approval; S.D.: data acquisition, revision, final approval; A.V.H.: data analysis and interpretation, revision, final approval; V.K.: data acquisition, interpretation, revision, final approval; W.J.: data acquisition, interpretation, revision, final approval; O.A.M.: concept and design, data acquisition, analysis and interpretation, revision, final approval.
}

Correspondence and requests for reprints should be addressed to Omar A. Minai, M.D., Department of Pulmonary, Allergy, and Critical Care Medicine, Cleveland Clinic, 9500 Euclid Avenue, Cleveland, OH 44195. E-mail: oam1998@outlook.com

This article has an online supplement, which is accessible from this issue's table of contents at www.atsjournals.org

Ann Am Thorac Soc Vol 11, No 7, pp 1056-1063, Sep 2014

Copyright (@) 2014 by the American Thoracic Society

DOI: 10.1513/AnnalsATS.201309-315OC

Internet address: www.atsjournals.org

Obstructive sleep apnea (OSA) occurs in approximately 5 to $10 \%$ of the population $(1,2)$. Studies have shown that patients with OSA have a higher mortality compared with those without OSA (3-5). This mortality risk has been attributed to various factors, including an increased incidence of coronary artery disease (CAD) (3-15), stroke (16), and autonomic dysfunction (17), and an increase in motor vehicle accidents from daytime somnolence (18). Impaired functional capacity (IFC) has been shown to be a good surrogate for total mortality in other diseases, but it is unknown if IFC predicts mortality in patients with $\operatorname{OSA}(21,22)$. In addition, although some studies have assessed the association of IFC and autonomic dysfunction in the OSA population, these studies have typically not taken CAD into account, despite its strong association 
with both IFC and autonomic dysfunction. It remains unknown whether IFC and autonomic dysfunction are associated with OSA if CAD is taken into account.

For our study, we chose a wellcharacterized cohort of patients with OSA who underwent a stress echocardiogram. Stress echocardiogram was used as the study parameter because it is one of the best methods of diagnosing CAD $(23,24)$ while also providing data on functional capacity. The aims of our study were to evaluate the risk factors associated with IFC in patients with OSA, to determine whether IFC predicts increased overall mortality in patients with OSA, and to explore a possible link between IFC and mortality in a subpopulation of patients with OSA without CAD.

\section{Methods}

\section{Patient Population}

Between 2003 and 2010, 59,466 patients had stress echocardiography performed and 11,256 patients underwent polysomnography (PSG) at our institution. There were 1,533 patients who had both a stress echocardiogram and PSG, and these formed our study population (Figure 1). All patients underwent a structured interview and chart review prior to their stress test. Data regarding demographics, testing indications, symptoms, risk factors, previous cardiac procedures, comorbidities, and medications were recorded. Mortality data were obtained from the social security database and a review of patient medical records.

All the patients underwent standard in-lab PSG. OSA was defined as an apneahypopnea index (AHI) of 5 or more events per hour of sleep and was graded as mild (AHI 5-15), moderate (AHI 16- 30), or severe $(\mathrm{AHI}>30)$.

\section{Exercise Testing}

After a supine resting ECG was obtained, symptom-limited exercise testing was conducted according to a standard protocol. An ischemic ST-segment response was defined as horizontal or down-sloping ST-segment depression of greater than or equal to $1 \mathrm{~mm}$ below baseline taken 80 milliseconds after the J-point if there was less than $1 \mathrm{~mm}$ of ST-segment depression at baseline. Functional capacity was measured in metabolic equivalents (METs).

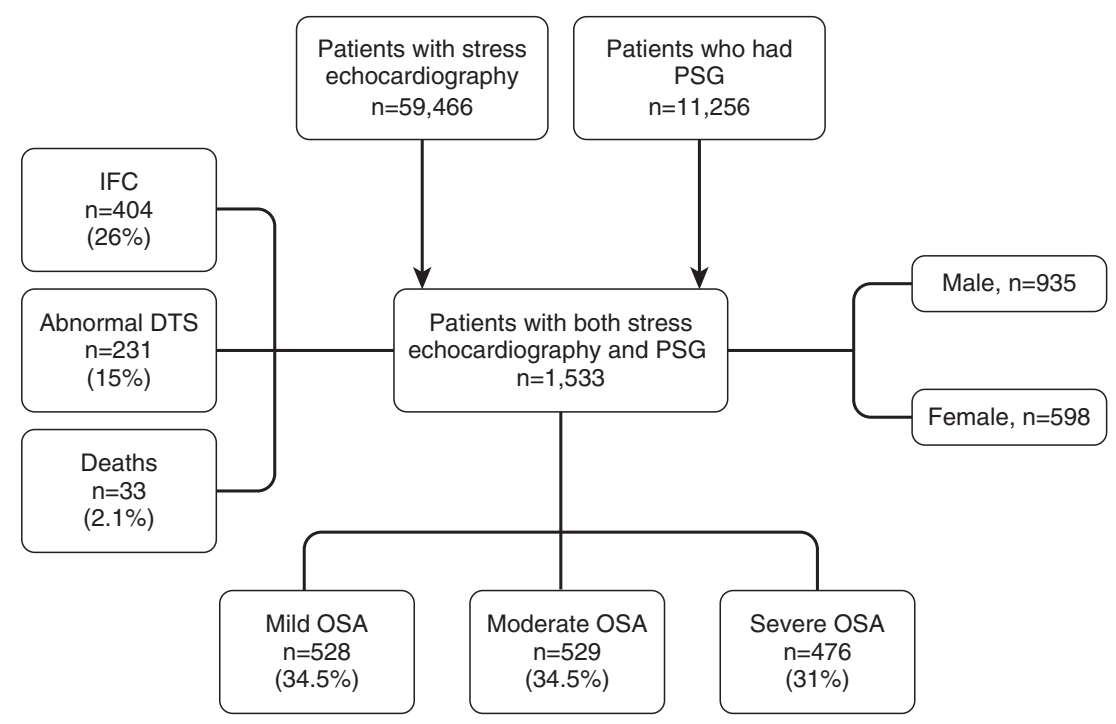

Figure 1. Overall study population. DTS = Duke treadmill score; IFC = impaired functional capacity; OSA = obstructive sleep apnea; PSG = polysomnography.
One MET is $3.5 \mathrm{ml} / \mathrm{kg} / \mathrm{min}$ of oxygen consumption (19). Patients who had fair or poor functional capacity for age and sex on the basis of a previously validated scheme from our laboratory were defined as having IFC (20). Specific cutoffs for IFC were less than 10 , less than 9 , less than 8 , less than 7 , and less than 6 METs for ages less than or equal to 29,30 to 39,40 to 49,50 to 59 , and greater than or equal to 60 years, respectively, for women; and less than 11, less than 10 , less than 8.5 , less than 8 , and less than 7 METs for ages less than or equal to 29 , 30 to 39,40 to 49,50 to 59 , and greater than or equal to 60 years, respectively, for men. Immediately after exercise, patients were asked to lie down in a supine position to perform a post stress echocardiogram. Heart rates were continuously monitored by computerized $\mathrm{R}-\mathrm{R}$ interval. An abnormal left ventricle test was defined as being scarred, ischemic, or nondiagnostic.

The Duke treadmill score (DTS) was accepted as a surrogate marker for the presence of $\operatorname{CAD}(23,24)$ and was calculated as follows: [duration of exercise (in minutes)] $[5 \times$ maximal ST-segment deviation during or after exercise (in millimeters)] [ $4 \times$ treadmill angina index $(0=$ no angina, $1=$ nonlimiting angina, 2 = exercise-limiting angina)]. A treadmill exercise score of 5 or greater was considered low risk; -10

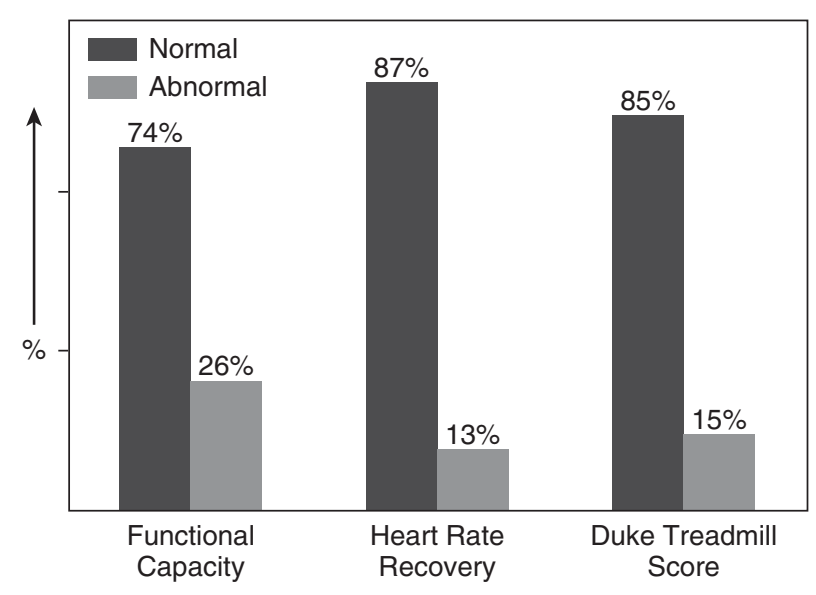

Figure 2. Characteristics of the overall study population $(n=1,533)$. 
to +4 , moderate risk; and less than -10 , high risk (21).

Two-dimensional echocardiography was performed before and immediately after exercise (22). Images were obtained in left lateral decubitus position with parasternal, long axis, short axis, apical, four chamber, and two chamber views using standard commercially available equipment. Images were interpreted by an attending cardiologist at our institution who was blinded to the study hypothesis, PSG results, and outcomes data. Left ventricular ejection fraction was estimated visually. Qualitative analysis was done in a standard 16segment model of the left ventricle to identify ischemia and infarction. There were no missing data for left ventricular ejection fraction, exercise hemodynamic variables, or stress echocardiographic variables.

Heart rate recovery (HRR) was measured as the difference between maximal heart rate and 1-minute heart rate immediately after peak exercise. Abnormal
HRR was defined as HRR less than or equal to 18 beats/min (23).

\section{Statistical Analyses}

Categorical variables are described as number and proportions. Continuous variables are described as mean and SD. Differences between the two groups were tested with the Chi-square test or the Fisher exact test for categorical variables and with the $t$ test or Wilcoxon rank sum test for continuous variables. The association between individual patient variables and

Table 1. Univariable analysis of patient characteristics and functional capacity in the study population $(\mathrm{N}=1,533)$

\begin{tabular}{|c|c|c|c|c|c|}
\hline \multirow[t]{2}{*}{ Variable } & \multirow[t]{2}{*}{$\mathbf{N}$} & \multicolumn{2}{|c|}{ IFC } & \multirow[t]{2}{*}{ Univariable OR $(95 \% \mathrm{Cl})$ for IFC } & \multirow[t]{2}{*}{$P$ Value } \\
\hline & & Yes $(n=404)$ & No $(n=1,129)$ & & \\
\hline Age, yr & & $54.6(13.0)$ & 54.3 (10.6) & $1.01(0.96-1.07)^{\star}$ & 0.6 \\
\hline Sleep apnea severity, n (\%) & 1,533 & & & & 0.2 \\
\hline Mild & 528 & $133(36)$ & $395(35)$ & $1^{\dagger}$ & \\
\hline Moderate & 529 & $131(32)$ & $398(35)$ & $1.0(0.7-1.3)$ & \\
\hline Severe & 476 & $140(35)$ & $336(30)$ & $1.2(0.9-1.6)$ & \\
\hline Abnormal renal function, $\mathrm{n}(\%)$ & 4 & $3(0.7)$ & $1(0.1)$ & $8.4(0.8-81.4)$ & 0.2 \\
\hline Smoking, n (\%) & 1,489 & & & & 0.02 \\
\hline No & 772 & $184(46)$ & $588(52)$ & $1^{\dagger}$ & \\
\hline Yes & 717 & $208(51)$ & $509(45)$ & $1.3(1.0-1.6)$ & \\
\hline Hypercholesterolemia, n (\%) & 1,482 & & & & 0.02 \\
\hline No & 570 & $172(43)$ & $398(35)$ & $1^{\dagger}$ & \\
\hline Yes & 912 & $224(55)$ & $688(61)$ & $0.8(0.6-1.0)$ & \\
\hline $\mathrm{EF}, \%$ & 1,493 & & & & 0.01 \\
\hline $\begin{array}{l}\geqslant 55 \\
<55\end{array}$ & $\begin{array}{r}1,394 \\
99\end{array}$ & $\begin{array}{c}355(88) \\
37(9)\end{array}$ & $\begin{array}{c}1,039(92) \\
62(5)\end{array}$ & $1.7 \underset{1^{\dagger}}{(1.1-2.7)}$ & \\
\hline LV test result, n (\%) & 1,484 & & & & $<0.0001$ \\
\hline Normal & 1,247 & $270(67)$ & $977(87)$ & $1^{\dagger}$ & \\
\hline Ischemic/scarred & 84 & $34(8)$ & $50(4)$ & $2.5(1.6-3.9)$ & \\
\hline Nondiagnostic & 153 & $83(21)$ & $70(6)$ & $4.3(3.0-6.1)$ & \\
\hline Male, n (\%) (vs. female) & 935 & $180(46)$ & $745(66)$ & $0.4(0.3-0.5)$ & $<0.0001$ \\
\hline Female, n (\%) (vs. male) & 598 & $224(54)$ & $384(34)$ & $2.5(2.0-3.3)$ & $<0.0001$ \\
\hline $\mathrm{BMI}, \mathrm{kg} / \mathrm{m}^{2}$ & & $35.8(7.3)$ & $30.8(5.2)$ & $2.0(1.8-2.2)$ & $<0.0001$ \\
\hline BMI category, n (\%) & 1,533 & & & & $<0.0001$ \\
\hline Normal $(<25)$ & 153 & $18(4)$ & $135(12)$ & $1^{\dagger}$ & \\
\hline Mild obesity (25-29.9) & 458 & $64(16)$ & $394(35)$ & $1.2(0.7-2.1)$ & \\
\hline Moderate obesity (30-39.9) & 759 & $217(54)$ & 542 (48) & $3.0(1.8-5.0)$ & \\
\hline Severe obesity $(\geqslant 40)$ & 163 & $105(26)$ & $58(5)$ & $13.6(7.5-24.4)$ & \\
\hline Diabetes, $\mathrm{n}(\%)$ & 1,259 & & & & $<0.0001$ \\
\hline No & 1,025 & $230(57)$ & $795(70)$ & $1^{\dagger}$ & \\
\hline Yes (DM1 or DM2) & 234 & $110(27)$ & $124(11)$ & $3.1(2.3-4.1)$ & \\
\hline Hypertension, n (\%) & 1,503 & & & & $<0.0001$ \\
\hline No & 679 & $143(35)$ & $536(47)$ & $1^{\dagger}$ & \\
\hline Yes & 824 & $259(64)$ & $565(50)$ & $1.7(1.4-2.2)$ & \\
\hline Heart rate recovery, $\mathrm{n}(\%)$ & 1,528 & & & & $<0.0001$ \\
\hline Normal & 1,335 & $306(76)$ & $1,029(91)$ & $1^{\dagger}$ & \\
\hline Poor/abnormal & 193 & $97(24)$ & $96(9)$ & $3.4(2.5-4.6)$ & \\
\hline Duke treadmill score, n (\%) & 1,533 & & & & $<0.0001$ \\
\hline Normal & 1,235 & $237(59)$ & $998(88)$ & $1^{\dagger}$ & \\
\hline Abnormal & 231 & $136(34)$ & $95(8.4)$ & $5.9(4.4-8.0)$ & \\
\hline Noninterpretable & 67 & $31(8)$ & $36(3)$ & $3.7(2.2-6.1)$ & \\
\hline
\end{tabular}

Definition of abbreviations: $\mathrm{BMI}=$ body mass index; $\mathrm{Cl}=$ confidence interval; $\mathrm{DM}=$ diabetes mellitus; $\mathrm{EF}=$ ejection fraction; $\mathrm{IFC}=$ impaired functional capacity; LV = left ventricle; OR = odds ratio.

Continuous variables reported as mean (SD) and categorical reported as $\mathrm{n}(\%)$

*Per 5-unit increase.

${ }^{\dagger}$ Reference category. 
Table 2. Multivariable analysis for predictors of impaired functional capacity adjusted for other patient characteristics $(N=1,533)$

\begin{tabular}{|c|c|c|}
\hline Variable & Multivariable OR $(95 \% \mathrm{Cl})$ for IFC & $P$ Value \\
\hline BMI, mean (SD) & $2.0(1.8-2.3)$ & $<0.0001$ \\
\hline \multicolumn{3}{|l|}{ Duke treadmill score } \\
\hline Normal & $1^{*}$ & $<0.0001$ \\
\hline Abnormal & $5.5(3.6-8.3)$ & \\
\hline Noninterpretable & $1.9(0.9-4.1)$ & \\
\hline Female (vs. male) & $2.0(1.4-2.5)$ & 0.0001 \\
\hline Male (vs. female) & $0.5(0.4-0.7)$ & 0.0001 \\
\hline \multicolumn{3}{|l|}{ Diabetes } \\
\hline $\begin{array}{l}\text { No } \\
\text { Yes (DM1 or DM2) }\end{array}$ & $2.1(1.4-3.0)$ & 0.0001 \\
\hline \multicolumn{3}{|l|}{ LV test result } \\
\hline $\begin{array}{l}\text { Normal } \\
\text { Ischemic/scarred } \\
\text { Nondiagnostic }\end{array}$ & $\begin{array}{c}1^{*} \\
1.9(1.0-3.8) \\
2.8(1.7-4.6)\end{array}$ & 0.0002 \\
\hline \multicolumn{3}{|l|}{ Heart rate recovery } \\
\hline $\begin{array}{l}\text { Normal } \\
\text { Poor/abnormal }\end{array}$ & $1.9(1.2-2.9)$ & 0.005 \\
\hline \multicolumn{3}{|l|}{ Hypercholesterolemia } \\
\hline $\begin{array}{l}\text { No } \\
\text { Yes }\end{array}$ & $0.7(0.5-0.9)$ & 0.01 \\
\hline \multicolumn{3}{|c|}{ (0.6) } \\
\hline $\begin{array}{l}<55 \\
\geqslant 55\end{array}$ & $\begin{array}{c}1.7(0.9-3.5) \\
1^{*}\end{array}$ & 0.1 \\
\hline \multicolumn{3}{|l|}{ Smoking } \\
\hline $\begin{array}{l}\text { No } \\
\text { Yes }\end{array}$ & $1.4(1.0-1.9)$ & 0.1 \\
\hline \multicolumn{3}{|l|}{ Hypertension } \\
\hline $\begin{array}{l}\text { No } \\
\text { Yes }\end{array}$ & $1.3(0.9-1.8)$ & 0.2 \\
\hline \multicolumn{3}{|l|}{ Sleep apnea severity } \\
\hline Mild & $0.9(0.7-1.3)$ & 0.5 \\
\hline Severe & $1.1(0.7-1.7)$ & \\
\hline
\end{tabular}

All variables with a $P \leqslant 0.2$ in univariable analysis are included in the multivariable analysis. Definition of abbreviations: $\mathrm{BMI}=$ body mass index; $\mathrm{Cl}=$ confidence interval; $\mathrm{DM}=$ diabetes mellitus; $\mathrm{EF}=$ ejection fraction; IFC = impaired functional capacity; $\mathrm{LV}=$ left ventricle; OR = odds ratio. *Reference category. outcomes was evaluated with univariable logistic regression analysis. Associations were expressed as odds ratios and their 95\% confidence intervals. Variables with a $P$ value less than or equal to 0.2 in univariable analysis were selected for multivariable logistic regression analysis. A $P$ value of less than 0.05 was considered significant. Overall survival was evaluated with life table analysis, and differences between subgroups were evaluated with the log-rank test. SAS 9.2 (Cary, NC) was used for all statistical analyses.

This study had no external funding source.

\section{Results}

\section{Clinical Characteristics and Functional Capacity}

A total of 1,533 patients met study criteria and were included in the analysis (Figure 1, Table 1). The mean age of our study participants was 54 years, $60 \%$ were men $(\mathrm{n}=925), 528(34.5 \%)$ patients had mild OSA, 529 (34.5\%) had moderate OSA, and 476 (31\%) had severe OSA. IFC was present in 404 (26\%) patients, and an abnormal DTS was present in 231 patients (15\%) (Figure 2).

\section{Predictors of Impaired Functional Capacity}

Overall, 404 (26\%) patients had IFC. The best predictors of IFC by univariable analysis and multivariable analysis are

Table 3. Predictors of overall mortality by univariable analysis

\begin{tabular}{|c|c|c|c|c|c|}
\hline \multirow[t]{2}{*}{ Variable } & \multirow[t]{2}{*}{$\mathbf{N}$} & \multicolumn{2}{|c|}{ Overall Mortality } & \multirow{2}{*}{$\begin{array}{l}\text { Univariable OR (95\% Cl) } \\
\text { for Overall Mortality }\end{array}$} & \multirow[t]{2}{*}{$P$ Value } \\
\hline & & Yes $(n=33)$ & No $(n=1,500)$ & & \\
\hline Functional capacity, n (\%) & 1,533 & & & & \\
\hline Normal & 1,129 & $12(36)$ & $1,117(74)$ & 1 & $<0.0001$ \\
\hline Impaired & 404 & $21(64)$ & $383(26)$ & $5.1(2.5-10.5)$ & \\
\hline Duke treadmill score, $\mathrm{n}(\%)$ & 1,533 & & & & \\
\hline Normal & 1,235 & $14(42)$ & $1,221(81)$ & 1 & $<0.0001$ \\
\hline Abnormal & 231 & $16(49)$ & $215(14)$ & $6.5(3.1-13.5)$ & \\
\hline Noninterpretable & 67 & $3(9)$ & $64(4)$ & $4.1(1.1-14.6)$ & \\
\hline Heart rate recovery, $\mathrm{n}(\%)$ & 1,528 & & & & \\
\hline Normal & 1,335 & $23(70)$ & $1,312(88)$ & 1 & 0.003 \\
\hline Poor/abnormal & 193 & $10(30)$ & $183(12)$ & $3.1(1.5-6.7)$ & \\
\hline Sleep apnea severity, n (\%) & 1,533 & & & & 0.2 \\
\hline Mild & 528 & $8(24)$ & $520(35)$ & 1 & \\
\hline Moderate & 529 & $10(30)$ & $519(35)$ & $1.3(0.5-3.2)$ & \\
\hline Severe & 476 & $15(45)$ & 461 (31) & $2.1(0.9-5.0)$ & \\
\hline
\end{tabular}

Definition of abbreviations: $\mathrm{Cl}=$ confidence interval; $\mathrm{OR}=$ odds ratio. 
presented in Tables 1 and 2, respectively. By multivariable analysis (Table 2), the best predictors of IFC were abnormal DTS, elevated body mass index (BMI), diabetes mellitus, and female sex.

\section{Predictors of Mortality}

Thirty-three $(2.1 \%)$ patients died during follow-up (median, $5.5 \mathrm{yr}$ [interquartile range, 3.7-7.9]). To avoid model overfitting, only four variables were studied as predictors of mortality. These variables were: severity of OSA, HRR, DTS, and IFC. Abnormal HRR, abnormal DTS, and IFC were predictive of total mortality by univariable analysis, and patients with IFC were 5.1 times more likely to die than those without IFC (Table 3). By KaplanMeier analysis, abnormal DTS (Figure 3A; $\log$ rank $P<0.0001$ ) and IFC (Figure 3B; $\log$ rank $P<0.0001$ ) were highly predictive of increased mortality. By multivariable analysis (Table 4), only IFC and abnormal DTS were predictive of total mortality. Patients with IFC were 2.7 times more likely to die compared with patients with normal functional capacity (Table 4). Mortality was lowest in patients with normal DTS and normal functional capacity and highest among patients with abnormal DTS and IFC (Figure 3C).

\section{Performance of IFC relative to DTS}

In the overall study population, $1,235(85 \%)$ patients had normal DTS and 231 (15\%) had abnormal DTS. Of those with normal DTS, 237 (19.2\%) had IFC (see Table E4 in the online supplement). In this cohort with normal DTS, those with IFC had a significantly higher risk of mortality relative to those with normal functional capacity (odds ratio, 4.31; 95\% confidence interval, $1.35-13.79 ; P=0.0088$ )

(Table 5). Of the 33 deaths, 16 patients had abnormal DTS (3 with normal functional capacity and 13 with IFC) and 14 patients had a normal DTS (7 with normal functional capacity and 7 with IFC). Three of the DTS were noninterpretable, of which two had IFC (Figure 4;

Table E1).

In the cohort with normal DTS, the best predictors of IFC by multivariable analysis included history of smoking, hypertension, hypercholesterolemia, age, abnormal left ventricle test on stress echocardiogram, HRR, female sex, diabetes, and BMI (Table E5).
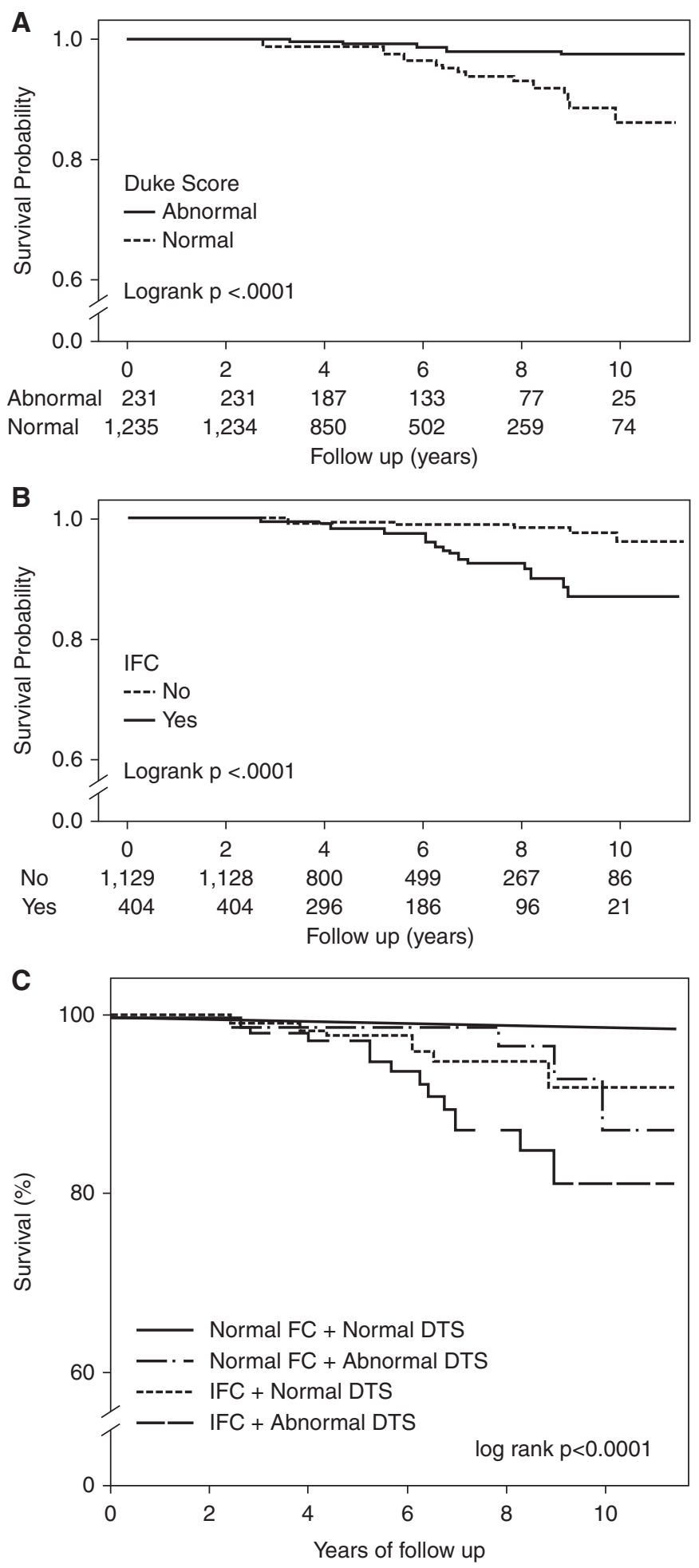

Figure 3. Kaplan-Meier survival curves comparing Duke treadmill score (DTS) and impaired functional capacity (IFC). FC = functional capacity.

\section{Discussion}

We report the results from a large database of well-characterized patients with OSA undergoing stress echocardiography, and our findings extend the literature in several important ways. We found that IFC was a strong predictor of increased mortality 
Table 4. Predictors of overall mortality by multivariable analysis

\begin{tabular}{|c|c|c|}
\hline Variable & $\begin{array}{l}\text { Multivariable OR } \\
(95 \% \mathrm{Cl}) \text { for } \\
\text { Overall Mortality }\end{array}$ & $P$ Value \\
\hline \multicolumn{3}{|l|}{$\begin{array}{l}\text { Duke treadmill } \\
\text { score }\end{array}$} \\
\hline $\begin{array}{l}\text { Normal } \\
\text { Abnormal } \\
\text { Noninterpretable }\end{array}$ & $\begin{array}{c}1 \\
4.1(1.8-9.3) \\
2.8(0.8-10.2)\end{array}$ & 0.003 \\
\hline \multicolumn{3}{|l|}{$\begin{array}{l}\text { Functional } \\
\text { capacity }\end{array}$} \\
\hline $\begin{array}{l}\text { Normal } \\
\text { Impaired }\end{array}$ & $2.7 \begin{array}{c}1 \\
(1.2-6.1)\end{array}$ & 0.02 \\
\hline \multicolumn{3}{|l|}{$\begin{array}{l}\text { Heart rate } \\
\text { recovery* }\end{array}$} \\
\hline Normal & 1 & 0.2 \\
\hline $\begin{array}{l}\text { Poor/abnormal } \\
\text { Sleep apnea } \\
\text { severity }\end{array}$ & $1.6(0.7-3.7)$ & \\
\hline Mild & 1 & 0.3 \\
\hline Moderate & $1.1(0.4-2.9)$ & \\
\hline Severe & $1.9(0.8-4.7)$ & \\
\hline
\end{tabular}

Definition of abbreviations: $\mathrm{Cl}=$ confidence interval; $\mathrm{OR}=$ odds ratio.

*Five living patients without information.

Table 5. Impaired functional capacity and mortality in patients without coronary artery disease $(n=1,235)$

\begin{tabular}{lrcr}
\hline & Alive & Dead & Total \\
$\begin{array}{l}\text { Normal DTS and } \\
\text { normal FC }\end{array}$ & 991 & 7 & 998 \\
$\begin{array}{l}\text { Normal DTS and } \\
\text { IFC }\end{array}$ & 230 & 7 & 237 \\
Total & 1,221 & 14 & 1,235 \\
\hline
\end{tabular}

Definition of abbreviations: $\mathrm{Cl}=$ confidence interval; DTS = Duke treadmill score; FC = functional capacity; IFC = impaired functional capacity; $\mathrm{OR}=$ odds ratio.

OR, 4.31; 95\% Cl, 1.35-13.79; $P$ value $=0.0088$

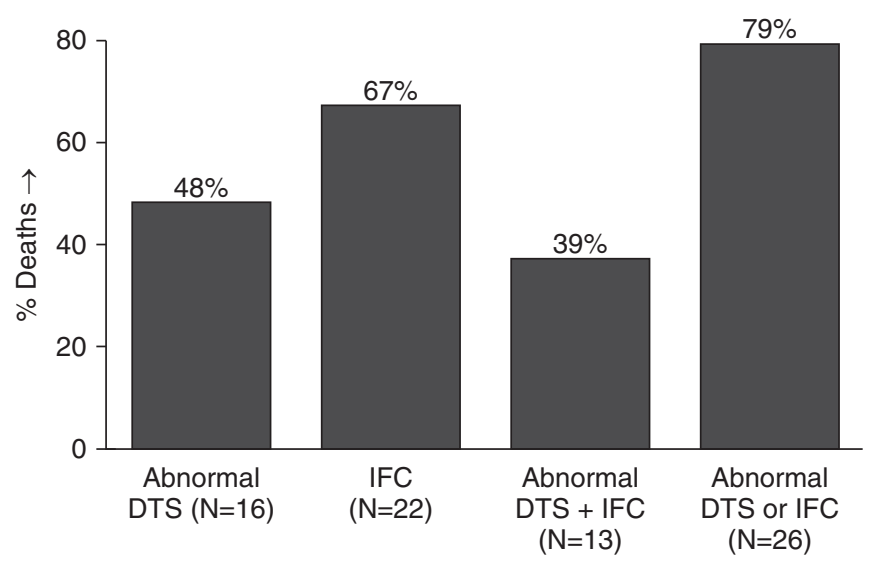

Figure 4. The addition of impaired functional capacity (IFC) increases the ability of stress echocardiography to predict mortality in patients with obstructive sleep apnea $(n=33)$. DTS = Duke treadmill score. among patients with OSA. We also found that IFC continued to be a significant predictor of mortality even in the non-CAD population. In addition, we report that a subgroup of patients with OSA with IFC and abnormal DTS had a higher mortality than those with either factor alone.

OSA has been recognized as a risk factor for increased total mortality in several studies $(3,4,14,29-35)$. IFC has been shown to be a strong predictor of all-cause mortality in a diverse patient population (20), and an association between IFC and OSA has also been reported (24). This association has been postulated to be the result of $\mathrm{CAD}$, autonomic dysfunction, obesity, and/or contribution from other comorbidities, such as diabetes and hypertension. This is the first study that shows that IFC is a strong predictor of mortality in a large, well-characterized cohort of patients with OSA.

The high prevalence of CAD in OSA $(6-18,38-45)$ is believed to be secondary to several mechanisms, including increased inflammation (25-27), endothelial dysfunction (28-30), platelet aggregation abnormalities $(31,32)$, hypoxia causing nocturnal ischemia $(33,34)$, and increased sympathetic tone (17). Given this overlap, it is imperative to exclude CAD when studying the factors responsible for IFC and the potential impact of IFC on mortality among patients with OSA. Due to limitations in sample size or patient data, previous studies have been unable to account for this in their analysis. Punjabi and colleagues analyzed a cohort of patients with OSA and found severe sleep-disordered breathing was associated with increased all-cause mortality in men, particularly in the 40- to 70-year age group after accounting for known confounding factors (35). Their study suggested that the increased risk of death might be associated with CAD. We accounted for CAD by using abnormal DTS as a validated surrogate for $\operatorname{CAD}(23,24,46,47)$. We found that IFC was a strong predictor of mortality among patients with OSA with normal DTS. This suggests that IFC can predict mortality in patients with OSA even after accounting for CAD. In addition, we identified a cohort of patients with both IFC and abnormal DTS who were at a higher risk of mortality than those having either factor alone. This has significant clinical implications and potentially identifies a previously 
undescribed high-risk group among patients with OSA referred for cardiac stress testing. These two findings suggest that the addition of IFC may be able to improve the ability of exercise stress testing to predict mortality in patients with OSA when DTS is normal and may also help identify a group of patients at especially high risk when IFC is found among patients with an abnormal DTS. Similar to an earlier study (36), we found that the presence of CAD (as determined by an abnormal DTS in our cohort) was the strongest predictor of survival by multivariable analysis in patients with OSA undergoing exercise stress testing.

In the overall cohort, as expected, abnormal DTS and abnormal stress echocardiogram, which are surrogates for $\mathrm{CAD}$, were important predictors of IFC. Other important predictors of IFC included diabetes, elevated BMI, abnormal HRR, and hypercholesterolemia, whereas hypertension, low ejection fraction, and OSA severity did not predict mortality. These findings are in agreement with previous studies that have looked at IFC and mortality in other disease cohorts (20,37). Among the cohort with normal DTS, predictors of IFC included increased age, history of smoking, hypercholesterolemia, hypertension, abnormal left ventricle test on stress echocardiogram, and increased $\mathrm{BMI}$, which are all risk factors for CAD. We postulate that IFC may be identifying a group of patients with normal DTS who are at increased risk of future development of CAD (20). As cardiovascular exercise programs improve functional capacity, patients with OSA with IFC may represent a group with potentially modifiable risk factors for mortality. Clinicians should be aware of the role of functional capacity assessment in order for new patient education strategies, which have the potential to impact mortality in patients with OSA, to be adopted.

OSA has been postulated to be associated with autonomic dysfunction. It has been theorized that nocturnal hypoxia may cause increased catecholamine release possibly leading to autonomic dysfunction (38-40), which is known to be associated with mortality (41-43). HRR after stress testing has been well recognized as a measure of autonomic function (44) and a risk factor for adverse clinical outcomes in several disease states $(48,49)$. Maeder and colleagues (50) studied HRR in patients with OSA and concluded that the severity of OSA, as defined by the AHI, was independently associated with abnormal HRR. Their study did not account for CAD even though the association between HRR and CAD is well known. In our cohort, reduced HRR was a predictor of IFC in patients without CAD. Even though reduced HRR was a predictor of increased mortality on univariable testing, it no longer predicted mortality when abnormal DTS and IFC were taken into account by multivariable analysis.

In our study, age was not a predictor for IFC in patients with OSA. This was an unexpected finding. Prior studies looking at functional capacity have shown age as a strong predictor of IFC (37). It is unclear whether the discrepancy in our results is due to the population being studied, as it only included individuals referred for exercise stress testing.

Major strengths of our study include the large, well-characterized OSA population and the long follow-up period. Our study has some limitations. This is a retrospective study; therefore, stress echocardiography and PSGs were not done concurrently, and the study population composed of only those who were referred for exercise testing may have resulted in a selection bias. Last, we obtained mortality data from the social security database, which is not a real-time database.

\section{Conclusions}

We found IFC was a strong predictor of increased mortality among patients with OSA and it continued to be a significant predictor of mortality even in the non-CAD population. These findings suggest that IFC can predict mortality in patients with OSA even after accounting for CAD. A subgroup of patients with OSA with IFC and abnormal DTS had a higher mortality than those with either factor alone. These patients represent a previously undescribed high-risk group among patients with OSA referred for cardiac stress testing. Our study suggests that the addition of IFC may be able to improve the ability of a stress test to predict mortality in patients with OSA when DTS is normal and may also help identify a group of patients at especially high risk when IFC is found among patients with an abnormal DTS.

Author disclosures are available with the text of this article at www.atsjournals.org.

\section{References}

1 Young T, Evans L, Finn L, Palta M. Estimation of the clinically diagnosed proportion of sleep apnea syndrome in middle-aged men and women. Sleep 1997;20:705-706.

2 Hiestand DM, Britz P, Goldman M, Phillips B. Prevalence of symptoms and risk of sleep apnea in the US population: results from the National Sleep Foundation Sleep in America 2005 poll. Chest 2006;130:780-786.

3 Yaggi HK, Concato J, Kernan WN, Lichtman JH, Brass LM, Mohsenin V. Obstructive sleep apnea as a risk factor for stroke and death. N Engl J Med 2005;353:2034-2041.

4 Marshall NS, Wong KKH, Liu PY, Cullen SRJ, Knuiman MW, Grunstein RR. Sleep apnea as an independent risk factor for all-cause mortality: the Busselton Health Study. Sleep 2008;31:1079-1085.

5 Partinen M, Jamieson A, Guilleminault C. Long-term outcome for obstructive sleep apnea syndrome patients. Mortality. Chest 1988; 94:1200-1204.

6 Andreas S, Schulz R, Werner GS, Kreuzer H. Prevalence of obstructive sleep apnoea in patients with coronary artery disease. Coron Artery Dis 1996;7:541-545.
7 Drager LF, Bortolotto LA, Lorenzi MC, Figueiredo AC, Krieger EM, Lorenzi-Filho G. Early signs of atherosclerosis in obstructive sleep apnea. Am J Respir Crit Care Med 2005;172:613-618.

8 Gami AS, Rader S, Svatikova A, Wolk R, Herold DL, Huyber C, Winnick M, Somers VK. Familial premature coronary artery disease mortality and obstructive sleep apnea. Chest 2007;131:118-121.

9 Hamilton GS, Solin P, Naughton MT. Obstructive sleep apnoea and cardiovascular disease. Intern Med J 2004;34:420-426.

10 Hayashi M, Fujimoto K, Urushibata K, Uchikawa S, Imamura H, Kubo K. Nocturnal oxygen desaturation correlates with the severity of coronary atherosclerosis in coronary artery disease. Chest 2003;124: 936-941.

11 Hu FB, Willett WC, Manson JE, Colditz GA, Rimm EB, Speizer FE, Hennekens $\mathrm{CH}$, Stampfer MJ. Snoring and risk of cardiovascular disease in women. J Am Coll Cardiol 2000;35:308-313.

12 Hung J, Whitford EG, Parsons RW, Hillman DR. Association of sleep apnoea with myocardial infarction in men. Lancet 1990;336: 261-264.

13 Marin JM, Carrizo SJ, Vicente E, Agusti AGN. Long-term cardiovascular outcomes in men with obstructive sleep apnoea-hypopnoea with or 
without treatment with continuous positive airway pressure: an observational study. Lancet 2005;365:1046-1053.

14 Mooe T, Franklin KA, Holmström K, Rabben T, Wiklund U. Sleepdisordered breathing and coronary artery disease: long-term prognosis. Am J Respir Crit Care Med 2001;164:1910-1913.

15 Mooe T, Rabben T, Wiklund U, Franklin KA, Eriksson P. Sleepdisordered breathing in women: occurrence and association with coronary artery disease. Am J Med 1996;101:251-256.

16 Mooe T, Rabben T, Wiklund U, Franklin KA, Eriksson P. Sleepdisordered breathing in men with coronary artery disease. Chest 1996;109:659-663.

17 Peker Y, Carlson J, Hedner J. Increased incidence of coronary artery disease in sleep apnoea: a long-term follow-up. Eur Respir J 2006;28:596-602.

18 Peker Y, Hedner J, Norum J, Kraiczi H, Carlson J. Increased incidence of cardiovascular disease in middle-aged men with obstructive sleep apnea: a 7-year follow-up. Am J Respir Crit Care Med 2002;166: 159-165.

19 Alonso-Fernández A, García-Río F, Racionero MA, Pino JM, Ortuño F, Martínez I, Villamor J. Cardiac rhythm disturbances and ST-segment depression episodes in patients with obstructive sleep apneahypopnea syndrome and its mechanisms. Chest 2005;127:15-22.

20 Young T, Blustein J, Finn L, Palta M. Sleep-disordered breathing and motor vehicle accidents in a population-based sample of employed adults. Sleep 1997;20:608-613.

21 Pitsavos $\mathrm{CH}$, Chrysohoou C, Panagiotakos DB, Kokkinos P, Skoumas J, Papaioannou I, Michaelides AP, Singh S, Stefanadis Cl. Exercise capacity and heart rate recovery as predictors of coronary heart disease events, in patients with heterozygous familial hypercholesterolemia. Atherosclerosis 2004;173:347-352.

22 Snader CE, Marwick TH, Pashkow FJ, Harvey SA, Thomas JD, Lauer MS. Importance of estimated functional capacity as a predictor of all-cause mortality among patients referred for exercise thallium single-photon emission computed tomography: report of 3,400 patients from a single center. J Am Coll Cardiol 1997; 30:641-648.

23 Mahenthiran J, Bangalore S, Yao S-S, Chaudhry FA. Comparison of prognostic value of stress echocardiography versus stress electrocardiography in patients with suspected coronary artery disease. Am J Cardiol 2005;96:628-634.

24 Marwick TH, Case C, Sawada S, Vasey C, Short L, Lauer M. Use of stress echocardiography to predict mortality in patients with diabetes and known or suspected coronary artery disease. Diabetes Care 2002;25:1042-1048.

25 Gibbons RJ, Balady GJ, Beasley JW, Bricker JT, Duvernoy WF, Froelicher VF, Mark DB, Marwick TH, McCallister BD, Thompson PD $\mathrm{Jr}$, et al. ACC/AHA guidelines for exercise testing. A report of the American College of Cardiology/American Heart Association task force on practice guidelines (committee on exercise testing). J Am Coll Cardiol 1997;30:260-311.

26 Shaw LJ, Peterson ED, Shaw LK, Kesler KL, DeLong ER, Harrell FE Jr, Muhlbaier LH, Mark DB. Use of a prognostic treadmill score in identifying diagnostic coronary disease subgroups. Circulation 1998;98:1622-1630.

27 Marwick TH, Mehta R, Arheart K, Lauer MS. Use of exercise echocardiography for prognostic evaluation of patients with known or suspected coronary artery disease. J Am Coll Cardiol 1997;30:83-90.

28 Watanabe J, Thamilarasan M, Blackstone EH, Thomas JD, Lauer MS. Heart rate recovery immediately after treadmill exercise and left ventricular systolic dysfunction as predictors of mortality: the case of stress echocardiography. Circulation 2001;104:1911-1916.

$29 \mathrm{He}$ J, Kryger MH, Zorick FJ, Conway W, Roth T. Mortality and apnea index in obstructive sleep apnea. Experience in 385 male patients. Chest 1988;94:9-14.

30 Young T, Finn L, Peppard PE, Szklo-Coxe M, Austin D, Nieto FJ, Stubbs R, Hla KM. Sleep disordered breathing and mortality: eighteen-year follow-up of the Wisconsin sleep cohort. Sleep 2008;31:1071-1078.

31 Lindberg E, Janson C, Svärdsudd K, Gislason T, Hetta J, Boman G. Increased mortality among sleepy snorers: a prospective population based study. Thorax 1998;53:631-637.
32 Ancoli-Israel S, Kripke DF, Klauber MR, Fell R, Stepnowsky C, Estline E, Khazeni N, Chinn A. Morbidity, mortality and sleepdisordered breathing in community dwelling elderly. Sleep 1996; 19:277-282.

33 Mant A, King M, Saunders NA, Pond CD, Goode E, Hewitt H. Four-year follow-up of mortality and sleep-related respiratory disturbance in non-demented seniors. Sleep 1995;18:433-438.

34 Ancoli-Israel S, Klauber MR, Kripke DF, Parker L, Cobarrubias M. Sleep apnea in female patients in a nursing home. Increased risk of mortality. Chest 1989;96:1054-1058.

35 Punjabi NM, Caffo BS, Goodwin JL, Gottlieb DJ, Newman AB, O'Connor GT, Rapoport DM, Redline S, Resnick HE, Robbins JA, et al. Sleep-disordered breathing and mortality: a prospective cohor study. PLoS Med 2009;6:e1000132.

36 Przybyłowski T, Bielicki P, Kumor M, Hildebrand K, MaskeyWarzechowska M, Korczyński P, Chazan R. Exercise capacity in patients with obstructive sleep apnea syndrome. J Physiol Pharmacol 2007;58:563-574.

37 Diaz LA, Brunken RC, Blackstone EH, Snader CE, Lauer MS. Independent contribution of myocardial perfusion defects to exercise capacity and heart rate recovery for prediction of all-cause mortality in patients with known or suspected coronary heart disease. J Am Coll Cardiol 2001;37:1558-1564

38 Kiely JL, McNicholas WT. Cardiovascular risk factors in patients with obstructive sleep apnoea syndrome. Eur Respir J 2000;16: 128-133.

39 Schäfer H, Koehler U, Ewig S, Hasper E, Tasci S, Lüderitz B. Obstructive sleep apnea as a risk marker in coronary artery disease. Cardiology 1999;92:79-84.

40 Silvestrini M, Rizzato B, Placidi F, Baruffaldi R, Bianconi A, Diomedi M. Carotid artery wall thickness in patients with obstructive sleep apnea syndrome. Stroke 2002;33:1782-1785.

41 Sorajja D, Gami AS, Somers VK, Behrenbeck TR, Garcia-Touchard A Lopez-Jimenez F. Independent association between obstructive sleep apnea and subclinical coronary artery disease. Chest 2008; 133:927-933.

42 Peker Y, Kraiczi H, Hedner J, Löth S, Johansson A, Bende M. An independent association between obstructive sleep apnoea and coronary artery disease. Eur Respir J 1999;14:179-184.

43 Shahar E, Whitney CW, Redline S, Lee ET, Newman AB, Nieto FJ, O'Connor GT, Boland LL, Schwartz JE, Samet JM. Sleep-disordered breathing and cardiovascular disease: cross-sectional results of the Sleep Heart Health Study. Am J Respir Crit Care Med 2001 163:19-25.

44 Udwadia ZF, Doshi AV, Lonkar SG, Singh CI. Prevalence of sleepdisordered breathing and sleep apnea in middle-aged urban Indian men. Am J Respir Crit Care Med 2004;169:168-173.

45 Koehler U, Schäfer H. Is obstructive sleep apnea (OSA) a risk factor for myocardial infarction and cardiac arrhythmias in patients with coronary heart disease (CHD)? Sleep 1996;19:283-286.

46 Alvarez Tamargo JA, Barriales Alvarez V, Sanmartín Pena JC, Hevia Nava S, Veganzones Bayón A, Simarro Martín-Ambrosio E, Cortina Llosa A. [Angiographic correlates of the high-risk criteria for conventional exercise testing and the Duke treadmill score]. Rev Esp Cardiol 2001;54:860-867.

47 Alexander KP, Shaw LJ, Shaw LK, Delong ER, Mark DB, Peterson ED. Value of exercise treadmill testing in women. J Am Coll Cardiol 1998:32:1657-1664.

48 Minai OA, Gudavalli R, Mummadi S, Liu X, McCarthy K, Dweik RA Heart rate recovery predicts clinical worsening in patients with pulmonary arterial hypertension. Am J Respir Crit Care Med 2012; 185:400-408.

49 Swigris JJ, Swick J, Wamboldt FS, Sprunger D, du Bois R, Fischer A Cosgrove GP, Frankel SK, Fernandez-Perez ER, Kervitsky D, et al. Heart rate recovery after 6-min walk test predicts survival in patients with idiopathic pulmonary fibrosis. Chest 2009;136: 841-848.

50 Maeder MT, Münzer T, Rickli H, Schoch OD, Korte W, Hürny C, Ammann $\mathrm{P}$. Association between heart rate recovery and severity of obstructive sleep apnea syndrome. Sleep Med 2008;9: 753-761. 